\title{
Avaliação dos Impactos da Política Pública de COTAS NA ÍNDIA
}

\section{Evaluation of the Impacts of the Public Policy FOR QUOTAS IN INDIA}

\section{Evaluación de los Impactos de la Política Pública de Cupos EN INDIA}

José Wilson Ferreira Lima* Bruno Amaral Machado**

1 Introdução. 2 O regime de cotas na Índia. 3 Sociedade, castas e identidade na Índia. 4 Desigualdade e sistema de cotas. 5 A persistência da exclusão na Índia. 6 Avaliação do impacto da política pública de cotas. 7 Conclusão. Referências.

\section{RESUMO}

O artigo tem por objetivo avaliar peculiaridades inerentes à adoção do sistema de cotas em contextos sociais, políticos e culturais distintos da sociedade brasileira. Pretende verificar o impacto que a adoção desse sistema proporcionou em termos de mudanças na ordem social da Índia. Diante dos estudos fundamentados, entende-se que a experiência adquirida em torno dos modelos de cotas que outros países adotaram fornece subsídios esclarecedores e significativos sobre como esses modelos podem operar transformações de acordo com as características de cada sítio de análise, cujas diferenças de organização social, política, econômica, jurídica e religiosa refletem os aspectos peculiares de cada modelo e, por esse motivo, como podem ser determinantes quanto ao seu sucesso ou ao seu fracasso. Assim, a avaliação dos impactos das políticas públicas instituídas no ambiente internacional pode

\footnotetext{
* Doutorando em Direito - Centro Universitário de Brasília. Mestre em Direito Constitucional - Instituto Brasiliense de Direito Público. Promotor de Justiça - Ministério Público do Distrito Federal e Territórios. E-mail: <wferreiraster@gmail.com>.http://orcid.org/0000-0002-9996-3485

** Doutor em Direito pela Universidade de Barcelona. Estágio de pós-doutorado no Departamento de Sociologia da Universidade de Brasília. Master Europeu do Programa Criminal Justice and Critical Criminology. Professor da Graduação e dos Programas de Mestrado e Doutorado em Direito do Uniceub. Professor do Programa de Doutorado em Ciências Penais da Universidade de San Carlos (Guatemala) e pesquisador do Departamento de Sociologia da Unb. E-mail: < brunoamachado@hotmail.com>.https://orcid.org/00000002-7425-7066
} 
ser providência útil para o Brasil, visando ao enfrentamento de futuras consequências decorrentes do emprego dessa modalidade de ação afırmativa.

Palavras-chave: Avaliação de Políticas Públicas. Ações Afirmativas. Cotas e Castas. Direitos Fundamentais. Inclusão e Exclusão.

\begin{abstract}
The purpose of this article is to evaluate the peculiarities inherent to the adoption of the quota system in social, political, and cultural contexts distinct from the Brazilian society. The intention is to verify the impact that the adoption of this system has caused in terms of possible changes in India's social order. It is understood that the experience achieved regarding quota models that other countries have adopted provides enlightening and meaningful subsidies on how these models can bring transformations according to the characteristics of each analyzed location, whose differences in social, political, economic, legal, and religious organization reflect the peculiarities of each model and, therefore, how they can be decisive for its success or failure. The evaluation of the impacts of public policies established in the international environment can be a useful measure for Brazil, aiming at facing the future consequences of implementing this kind of affirmative action.
\end{abstract}

Keywords: Evaluation of Public Policies. Affirmative Actions. Quotas and Castes. Fundamental Rights. Inclusion and Exclusion.

\title{
RESUMEN
}

El artículo tiene como objetivo evaluar las peculiaridades inherentes a la adopción del sistema de cupos en contextos sociales, políticos y culturales diferentes de la sociedad brasileña. Pretende verificar el impacto que la adopción de ese sistema ha proporcionado en términos de cambios en el orden social de India. Se comprende que la experiencia adquirida de los modelos de cupos que otros países han adoptado genera recursos aclaradores y significativos sobre cómo pueden provocar transformaciones de acuerdo con las características de cada sitio de análisis, cuyas diferencias de organización social, política, económica, jurídica y religiosa reflejan los aspectos peculiares de cada modelo y, por ese motivo, cómo pueden ser determinantes en cuanto a su éxito o fracaso. La evaluación de los impactos de las políticas públicas instituidas internacionalmente puede ser una medida útil para el Brasil con miras al enfrentamiento de las futuras consecuencias generadas del uso de esa modalidad de acción afirmativa.

Palabras clave: Evaluación de políticas públicas. Acciones afirmativas. Cupos y castas. Derechos fundamentales. Inclusión y exclusión. 


\section{INTRODUÇÃO}

Argumenta-se que as ações afirmativas têm elevado potencial transformador da sociedade e, por conseguinte, essa característica reforça e fundamenta a necessidade de se considerar as várias possibilidades, negativas e positivas, de como esse mecanismo transformador pode influenciar no futuro das próximas gerações, assim como fundamentar o propósito acadêmico de analisar e investigar os novos rumos que a sociedade brasileira, mestiça e, majoritariamente, pobre, seguirá em razão da adoção do sistemas de cotas como portal de acesso ao ensino universitário público e também a cargos e a empregos públicos (DUARTE; GUELFI, 2012, p. 121).

O objetivo deste estudo se limita a analisar, no plano internacional, particularidades próprias e decorrentes da adoção do sistema de cotas em planos sociais, políticos, culturais e até mesmo religiosos distintos daqueles que caracterizam a sociedade brasileira, de modo a buscar parâmetros sobre possíveis avanços ou retrocessos que esses sistemas possam ter produzido, considerando a necessidade de satisfação dos direitos fundamentais de forma abrangente. Pretende-se verificar, em particular, o impacto que a adoção das cotas proporcionou em termos de eventuais mudanças nas relações sociais, na atualidade, em relação ao modelo instituído na Índia, reconhecida como sociedade permeada por sérios problemas de desigualdades e de violações dos direitos humanos.

O recorte do objeto da pesquisa, limitado ao país indicado, é apropriado a partir do momento em que a Índia adotou modelo diferenciado e muito específico de política de cotas, o qual fornece subsídios esclarecedores e significativos sobre como essa política pode operar transformações de acordo com as características próprias desse sítio específico de análise, cujas diferenças de organização social, política, econômica, jurídica e religiosa são singulares e podem servir de importantes referenciais sobre o assunto.

Busca-se, com isso, o conhecimento sobre a funcionalidade das cotas vigentes na Índia, em seus aspectos mais significativos e, especialmente, em razão dos seguintes fatores: i) o referido país percorreu caminho diferente do percorrido pelo Brasil até atingir a atual conformação de seu regime político e de seu desenho social, a partir de experiências particulares; ii) entre a sociedade indiana e a brasileira, não há marcos referenciais de identidade ou de afinidade que lhes sejam comuns, de modo que a construção social de cada uma e seus respectivos valores se perfilaram em torno de padrões próprios de organização, cultura, religiosidade, desenvolvimento humano etc., com critérios diferenciados; iii) é certo que os fatores históricos que presidiram a formação dessas sociedades não tiveram influências mútuas; iv) em consequência do regime de organização social isolado e desconectado entre Índia e Brasil, não se pode atribuir que eventuais fracassos ou sucessos experimentados por um desses países possam concorrer para eventuais avanços ou retrocessos do outro, como se o modelo de cotas que cada um adotou tivesse pontos de contatos comuns que pudessem refletir, interna e externamente, nos limites geopolíticos de cada uma dessas sociedades. 
Enfim, são modelos independentes. Desse modo, a experiência da Índia, quanto ao sistema de cotas, é particularmente importante para a história, quanto às reais consequências dos programas de ações afirmativas, notadamente porque muito do que se passou naquele país foi o prenúncio do que ocorreu mais tarde em outros países, que seguiram o exemplo indiano de instituição de programas de ações afirmativas (SOWEL, 2016, p. 71-72). Ademais, a avaliação sobre o impacto de políticas públicas instituídas no ambiente internacional e com especial conformação em torno dos sistemas de cotas pode ser uma providência que ajudará a compreender de forma sistematizada como a Índia tem se comportado diante das consequências advindas da implantação dessa ação afirmativa.

Com efeito, reconhece-se a necessidade de se adensar o debate sobre as categorias jurídicas e experiências que possam subsidiar o enfrentamento de novos desafios em torno de programas de ações complexas (COUTINHO, 2013, p. 187-188), como é o caso das ações afirmativas instrumentalizadas mediante o emprego de cotas. A avaliação sobre o emprego destas e dos seus resultados no ambiente internacional pode constituir valoroso e útil método para dar suporte às novas decisões e aos debates quanto aos sistemas de cotas instituídos no Brasil.

Acrescente-se que essa perspectiva também se justifica devido ao fato de que, em regra, os objetivos das políticas públicas raramente são clarificados pelo legislador ou porque há outros caminhos que poderiam ser seguidos, com diferentes modos de serem alcançados, ou porque essas políticas estão constantemente sujeitas a novas adaptações, a ajustes, a avaliações, a revisões e a aprendizados (COUTINHO, 2013, p. 188).

\section{O REGIME DE COTAS NA ÍNDIA}

A discriminação sistemática vivenciada na Índia em razão da adoção do modelo social fundado em castas tem sido questão profunda, sensível e extremamente politizada, mesmo considerando as expressas disposições constitucionais e legislativas definidas para a proteção das pessoas socialmente excluídas naquele país. O sistema de castas indiano pode ser sintetizado como modelo de estratificação social que se define pela formação de grupos endogâmicos e hereditários, denominados castas, estimando-se que estas tenham surgido há 3000 anos (HOWARD; PRAKASH, 2011, p. 4).

Casta, por definição, é um vocábulo de origem portuguesa, a partir do latim castus, e consiste em uma organização grupal, socialmente fechada, que pratica a endogamia (MASCARENHAS, 1924, p. 27). É o modelo praticado na sociedade indiana, que se operacionaliza mediante estruturas hierarquizadas, divide a sociedade em grupos superiores ou puros e em grupos inferiores ou impuros, proíbe casamentos mistos e fixa a própria divisão de trabalho (WADE, 2015, p. 16). Por conseguinte, a adoção do sistema de castas implica três situações: i) a especialização hereditária, ii) a organização hierárquica e iii) a repulsa mútua. Consequentemente, uma casta pode estar situada em uma posição cimeira da hierarquia não pelo fato de obter obediência das outras, mas porque está mais próxima de um 
determinado valor. No caso indiano, a casta cimeira é a que está mais distante da impureza da vida animal (MALTEZ, 2009, p. 1).

Com efeito, o sistema de castas indiano é baseado numa rígida hierarquia social que atribuiu aos "intocáveis" (untouchables) a posição social mais baixa (CHANDOLA, 1992, p. 102), sendo largamente referenciado como fonte de desigualdades e de segregação social (VITHAYATHIL; SINGH, 2012, p. 60). Nessa ordem, a opressão baseada em castas na Índia vive hoje num ambiente aparentemente hostil à sua presença, caso se considere, por exemplo, a existência de leis destinadas a proscrever e a punir atos de discriminação com base em castas e os programas de ações afirmativas que incluem cotas constitucionalmente destinadas para os "intocáveis". Entretanto, paradoxalmente, questiona-se como e por que essa fórmula, visando à igualdade e ao nivelamento, tem feito tão pouco para mitigar séculos de opressão e de exclusão para mais de 167 milhões de dalits ou oprimidos (NARULA, 2008, p. 255).

A Índia dos dias atuais, com uma população total superior a 1,3 bilhões de habitantes, orienta-se pela conjugação do modelo social de castas e da experiência política das cotas, sendo estas exemplos dos meios empregados com a pretensão de se buscar algum nível de equilíbrio social, visando, com isso, a alcançar medidas que favoreçam avanços no campo do desenvolvimento humano. Nessa ordem, a Constituição da Índia reconhece cada indivíduo como igual, garantindo, portanto, o Direito à Igualdade como expressão de direito fundamental e assume que, em razão dele, são proibidas discriminações de qualquer natureza (SOWEL, 2016, p. 40), a exemplo da religião, da raça, da casta, do gênero ou da origem, como também tutela a igualdade de oportunidades em matéria de empregos e de outros direitos de envergadura social e econômica (CENTRE FOR BUDGET AND GOVERNANCE ACCOUNTABILITY, 2015, p. 2).

Desse modo, ao menos formalmente, o Estado indiano promete igualdade para todos os cidadãos, mediante direito reconhecido na Constituição e, para esse fim, são inúmeras as normas que tratam da obrigação de o Estado proporcionar iguais oportunidades para todos nas esferas social, política e econômica (HARRISS-WHITE; PRAKASH, 2010, p. 4). Entre as diferentes alternativas em políticas públicas sociais, nota-se que o Estado indiano incorporou as ações afirmativas. Todavia, interessa observar que, naquele país, o uso dessas ações pode ser compreendido como resultado de circunstâncias sociais, culturais, étnicas, geográficas, históricas, políticas e demográficas, devendo-se enfatizar que as discriminações orientadas pelas castas e pelos gêneros estão profundamente enraizadas na educação sociocultural, política e psicológica do povo (GUPTA, 2006, p. 5).

Diante dessa realidade, é importante ter em conta que a estrutura da ordem social na Índia se orienta pelo critério da hierarquização, especialmente quanto às tradições religiosas, da qual o povo indiano representa $82 \%$ da população (KUMAR, 2014, p. 36), o que equivale, em números atuais, a aproximadamente 1,1 bilhões de indivíduos. Devido a isso, exclusão social pode se referir, na Índia, a processos com várias dimensões, com várias combinações de 
exclusões que se associam à possibilidade de afastamento do núcleo de tomada de decisões no processo político, do acesso aos empregos e aos recursos materiais e até do processo de integração cultural (KUMAR, 2014, p. 37). Ao lado disso, há os constantes conflitos, por situações comuns e ideológicas, que elevam os níveis de violência na sociedade e fomentam mais exclusões, formais e informais, com reflexos na intensificação das desigualdades sociais (KUMAR, 2014, p. 47). Em acréscimo, avalia-se a questão do controle político sempre presente, argumentando-se que, por esse viés, as políticas baseadas no reconhecimento de que certos grupos são sub-representados podem ser vistas com o sentido de controle político e que, em certas circunstâncias, o reconhecimento de grupos baseados no gênero pode ser menos perturbador para as relações de poder do que o reconhecimento de grupos mais claramente identificados em classes sociais (RAI, 1999, p. 89).

Frente a essa particularidade, vale conferir que atualmente a ordem social indiana comporta castas (tradicionais) ou estruturas sociais distintas decorrentes da orientação religiosa hindu: Brahmins, Rajanya, Vaishyas e Shudras. Paralelamente a essa composição, identificam-se três grupos também distintos decorrentes da classificação estatal, que são: i) Scheduled Castes (SCs), ii) Scheduled Tribes (STs) e iii) Other Backward Classes (OBCs). Entretanto, não há nenhuma definição de critérios precisos (objetivos) sobre como eleger o status individual quanto à casta ou à tribo de pertencimento, de modo que, devido a essa imprecisão, tem-se a porta aberta para algumas práticas arbitrárias (CASSAN, 2014, p. 4).

Ademais, uma importante característica para a estabilização das castas indianas foi a restrição de mobilidade entre elas, de maneira que o nascimento em uma casta em particular confina a pessoa a permanecer nela e restringe sua mobilidade para cima ou para baixo na hierarquia (DESHPANDE, 2010, p. 17). Assim, diante das inúmeras fragilidades sociais e individuais que caracterizam a maioria da população indiana, consideradas como desvantagens históricas dos grupos, o Governo fez uso de ações afirmativas como instrumento político especialmente dirigido para corrigir graves distorções sociais. Para atingir esse propósito, a Constituição da Índia estipulou que cada Estado deverá reservar vagas de emprego no setor público para os integrantes das SCs e das STs, reconhecendo-as como as principais classes em desvantagens naquele país (PRAKASH, 2009, p. 1). Nesse contexto, justifica-se que, em resposta ao ônus do estigma social e do atraso econômico suportados pelos integrantes das castas inferiores, a Constituição tenha estabelecido disposições especiais que favorecessem os membros desses grupos (BOROOAH, 2005, p. 399).

A propósito, impõe-se considerar que, à medida que a Índia assumiu a atual conformação política (período pós-independência, que ocorreu em 1947), questões complexas sobre o sistema de castas ocuparam os debates, especialmente quanto à necessidade de elaboração da Constituição e do estabelecimento de nova ordem social. Naquele momento, os argumentos foram lançados em termos filosóficos e pragmáticos, entendendo-se que uma política de igualdade não poderia ser produzida sem que se buscasse igualdade social e econômica (RAI, 1999, p. 89). No entanto, hoje, diante do quadro político global, afirma-se que a Índia tem a 
sociedade mais multiétnica do mundo e, nessa mesma medida, a mais fragmentada do ponto de vista social, tratando-se de comunidade com centenas de línguas e centenas de dialetos, sendo também onde mais intensamente se manifestam os regimes das castas, das divisões étnicas e das tradições religiosas, que se expressam de formas radicalmente variadas, além de ser a nação com o mais longo histórico de ações afirmativas (SAREEN; SHAH, 2013, p. 6).

Em verdade, embora a Constituição tenha fixado cotas para as SCs e STs por um período de dez anos, o fato é que elas foram frequentemente estendidas, sem que houvesse qualquer discussão ou debate político pelo Parlamento (HEYER; JAYAL, 2009, p. 15). Cumpre esclarecer a esse respeito que as reservas originais especificadas na Constituição da Índia, aprovadas em novembro de 1949, expirariam no ano de 1960. Todavia, elas foram prorrogadas várias vezes e, em razão disso, em todas as instituições de Ensino Superior controladas pelo Governo Federal, 7,5\% dos lugares foram reservados para as STs e 15\% reservados para as SCs, não havendo, porém, reservas em favor das OBCs nessas instituições (BERTRAND; HANNA; MULLAINATHAN, 2010, p. 18).

As ações afirmativas, ou Reservation System, como são chamadas na Índia, são políticas produzidas com a pretensão de alcançar nivelamento social e, normalmente, implicam que um tipo de cota seja reservado para uma categoria especial de pessoas (KEDIA, 2015, p. 2). Nesse contexto, as reservas podem ser agrupadas e especialmente destinadas para as categorias da política, da educação e do emprego (JANGIR, 2013, p. 126). Entretanto, curiosamente, chama a atenção a circunstância a que tais reservas foram destinadas - oficialmente - apenas em favor das SCs e STs, todavia não beneficiaram as OBCs.

Nesse aspecto, convém observar que tal situação decorre de expressa determinação legal, a qual assegura que as principais categorias de ações afirmativas devem ser destinadas para as SCs e as STs, tudo de acordo com o texto constitucional (KEDIA, 2015, p. 3). De qualquer modo, vale conferir que a reserva de cotas associada ao sistema de castas, atendendo-se às intenções dos legisladores constituintes, teve a pretensão de garantir o estabelecimento da igualdade e da fraternidade, e não a separação e a discórdia (KEDIA, 2015 , p. 4). Não obstante, as vagas reservadas para os membros das OBCs, grupos dos menos favorecidos, são menos prevalentes (SAREEN; SHAH, 2013, p. 14). Desse modo, embora a Constituição ostensivamente proibisse a discriminação contra as $\mathrm{OBCs}$, o fato é que não foram instituídas políticas específicas de ações afirmativas para elas. Com efeito, já no ano de 1953, o Governo Federal formou comissão para estudar a situação das OBCs, de modo que, posteriormente, a comissão recomendou que 2399 castas "atrasadas" adicionais, que somariam aproximadamente $40 \%$ da população, também fossem favorecidas com as reservas (BERTRAND; HANNA; MULLAINATHAN, 2010, p. 18).

Feitos esses esclarecimentos, passa-se a conferir como se tem articulado os dois grandes eixos da história indiana, mediante a conexão entre o milenar e, provavelmente, mais antigo sistema de ordenação social - de castas - do mundo, acreditando-se que, historicamente, tenha se iniciado com a chegada dos conquistadores arianos na Índia, em torno de 1.500 a.C 
(DESHPANDE, 2010, p. 19), e que ainda se mantém como importante referencial histórico, sociológico e religioso, ao lado do sistema de cotas, presente na história recente de alguns países, incluindo-se o Brasil. Nesse aspecto, destaca-se que o regime de castas não é tipo de organização social privativo da Índia, pois também existiu no Egito e na Pérsia, assim como em quase todas as regiões invadidas pelos povos arianos (MASCARENHAS, 1924, p. 28).

\section{SOCIEDADE, CASTAS E IDENTIDADE NA ÍNDIA}

Pode-se afirmar que, na Índia, o seu sistema de castas equivale a um modelo de apartheid oculto, especialmente por se tratar de sociedade rigidamente estratificada, na qual cada nível de estratificação está associado a grupos muito específicos de pessoas e às respectivas funções que podem desempenhar. Nesse modelo, os Brahmins exercem funções próprias de sacerdotes, eruditos e professores; os Kshatriyas (Rajanyas) são os que exercem os governos e as funções dignatárias e militares; os Vaishyas exercem o comércio, os negócios e o artesanato, enquanto os Shudras atuam como prestadores de serviços, agricultores e operários.

Todavia, nessa organização, destaca-se a casta mais baixa, que corresponde aos grupos dos excluídos. São pessoas consideradas párias, escórias, a quem geralmente são impostas atividades tipicamente sujas e ritualmente poluidoras, como os serviços com o couro e a limpeza de esgoto (PAZICH, 2015, p. 141-142). De fato, há rigorosamente uma equivalência de cada casta com uma atividade vocacional predeterminada, como a predisposição para a atividade religiosa, que destaca a ética a qual valoriza o sagrado, do que decorre, por exemplo, normas e valores, padrões culturais, etiquetas, usos e costumes, tudo a compor regras que definem os sentidos pessoais das ações, assim como as relações sociais (HIRANO, 2002, p. 31). Nesse ciclo de relações, casta corresponde à sagração de cada ação social produtiva como resultante, em termos de imputação causal, de uma vocação (predestinação) profissional adstrita pela religião (HIRANO, 2002, p. 32). Percebe-se, nessa ordem, o caráter preponderante da casta como construção religiosa (MEHRA, 2007, p. 85).

Por conseguinte, a classe de pertencimento das pessoas mais empobrecidas e desamparadas passou a ser denominada de dalits, sendo reconhecida historicamente como a classe dos "intocáveis", devido à untoucheability (SOWEL, 2016, p. 42), isso porque, com as pessoas assim classificadas, não se mantêm contatos físicos, porque são impuras (PAZICH, 2015, p. 142), para não se utilizar de termos, como sujas ou imundas.

Assim, por causa dessas particularidades, historicamente associadas à classe dos dalits, resultou que eles são mantidos em povoados distantes dos centros e, portanto, convenientemente isolados dos grupos de castas mais elevadas, de modo a se evitar consequências mais graves (SOWEL, 2016, p. 42-43). Os dalits, nesse contexto, também são considerados unseeable, o que significa dizer que "não podem ser vistos". Além disso, é importante ressaltar que cada casta pode possuir centenas de subcastas, o que intensifica e proporciona mais diferenciações regionais, ocupacionais, linguísticas e sectárias (PAZICH, 2015, p. 142). 
Devido a isso, na atualidade, nem o Governo sabe quantas e quais são as castas e subcastas, estimando-se que há mais de quatro mil castas e centenas de dialetos, além das línguas oficiais, o hindi e o inglês, o que vai contra o plano anterior definido por Mohandas Gandi, o "Reformador", que havia fixado apenas quatro castas (as tradicionais) e que entre elas não haveria graus de superioridade ou inferioridade (CAMPOS NETO, 2009, p. 83; (DUARTE; GUELFI, 2012, p. 155). O que se destaca, portanto, é que "as quatro castas clássicas da religião hindu estão fragmentadas em, literalmente, milhares de castas e subcastas locais, as quais, na realidade, circunscrevem a vida social das pessoas." (SOWEL, 2016, p. 46).

A palavra untoucheability, enfim, é o atributo que se aplica ao mais baixo status na tradicional hierarquia das castas indianas, cujos membros são expostos a situações debilitadoras, a deficiências severas e a privações de oportunidades econômicas, sociais, culturais e políticas (HOWARD; PRAKASH, 2011, p. 5). Entretanto, não se pode desconsiderar que essa conformação social em torno das castas decorre da perspectiva filosófico-religiosa em torno da qual há consenso entre os estudiosos de que os chamados textos bramânicos, datados de 1.700 a 1.100 a.C., dispuseram sobre uma organização social que se teria como fundacional, de onde as partes do corpo de um ser originário - espécie de divindade - teriam dado origem aos grupos ou às castas, as quais teriam funções sociais específicas (HOFBAUER, 2015, p. 155) (DUARTE; GUELFI, 2012, p. 151). Desse modo, nessa primeira conformação da ordem social indiana, já se fazia referência à cor das pessoas. Com isso, as de cor clara (brancas) seriam entendidas como portadoras da luz e, devido a esse atributo, deveriam expulsar a escuridão e a ignorância, metaforicamente correspondendo às pessoas não claras (HOFBAUER, 2015, p. 156).

Para além desse recorte filosófico-religioso, considera-se que a sociedade indiana é, por longo tempo, sensível à diferença de cores, inclusive da pele, sendo tendenciosamente atraída para valorizar a cor mais clara, associando-a a ideais estéticos. Essa perspectiva parece ter se fortalecido a partir de novos estímulos decorrentes do contato com o mundo ocidental, desde o seu período colonial (HOFBAUER, 2015, p. 158).

Some-se a isso que, ao lado da realidade que envolve os processos identitários próprios do povo, enquanto os partidos políticos na Índia se envolveram com o processo de construção da identidade (KUMAR, 2014, p. 37), a política estatal foi claramente a que mais teve a ver com a dinamização dos conflitos baseados na identidade, uma vez que a orientação predominante para a resolução de conflitos foi estatal. Desse modo, não surpreende que o Estado tenha se tornado o alvo da mobilização política em favor dos grupos desfavorecidos, devido à percepção difundida de que o Estado é o depósito de valiosos recursos sociais, materiais e políticos, isto é, a fonte de todos os recursos (HEYER; JAYAL, 2009, p. 17).

\section{DESIGUALDADE E SISTEMA DE COTAS}

O setor da organização indiana que mais se beneficiou com o sistema de reservas (cotas) foi o da educação superior, cuja política foi a mais ampla e a de mais longa dura- 
ção no mundo, sendo destinada aos estudantes oriundos das castas mais baixas. Na Índia, esse sistema de reservas encontrou amparo em normas constitucionais e buscou favorecer os grupos catalogados (Scheduled Groups: Scheduled Castes (SCs) e Scheduled Tribes (STs)), mediante financiamentos prestados pelo Governo Federal (PAZICH, 2015, p. 142-143), tratando-se de espécie de "sistema mínimo garantido", isso porque são as cotas que devem ser preenchidas em primeiro lugar, enquanto as vagas restantes se destinam ao sistema de mérito (KEDIA, 2015, p. 5).

A adoção e a implantação de cotas na Índia é anterior à sua independência, que ocorreu no ano de 1947, havendo registros de que, no ano de 1891, no Estado de Kerala, já se fazia a reserva de vagas na esfera do Governo (serviço público), como forma de oposição ao recrutamento de servos civis; no ano de 1902, registrou-se a implantação da política de cotas no Estado de Kolhapur, na região central do país, procedendo-se à reserva de 50\% dos cargos da administração pública local em favor das chamadas "classes atrasadas" (Backward Classes), tratando-se, portanto, de grupos de pessoas desfavorecidas (PAZICH, 2015, p. 143).

Verificou-se que, em Kerala, o sistema de cotas contribuiu, particularmente, para a modificação do status social feminino, isso porque as mulheres passaram a ter elevado seu nível de instrução, fazendo que esse Estado apresentasse os mais altos resultados em termos de políticas afirmativas no contexto da atual sociedade indiana (PAZICH, 2015, p. 148). Quanto aos empregos, pôde-se constatar, posteriormente, que as oportunidades surgiram em favor das mulheres em Kerala devido à circunstância de terem adquirido razoável nível de instrução, de modo que esse benefício propiciou que elas pudessem exercer ofícios como os de parteira e de professora, conferindo-lhes maior ascensão social.

Como reflexo dessa política desenvolvida em Kerala, o grupo denominado Nair, pertencente às famílias das baixas castas, passou a servir como modelo de referência, uma vez que os demais grupos se espelhavam nele, especialmente, mas não apenas, em razão da ascensão social de suas mulheres (PAZICH, 2015, p. 149). Aliado a isso, os Nair passaram a gozar de nível incomum de mobilidade social, tanto que se passou a admitir que mantivessem relações com os Brahmins (casta de nível mais elevado) (PAZICH, 2015, p. 148-149).

Considera-se, atualmente, que os incentivos que favoreceram a empregabilidade em Kerala foram importantes fatores que possibilitaram, ao menos, às mulheres oriundas das baixas castas terem acesso à educação, usufruindo, nesse aspecto, da qualidade da educação superior britânica introduzida na Índia no século XIX. Embora se reconheça que apenas alguns grupos se beneficiaram desse padrão de educação, o maior impacto dessa política foi o de permitir que tanto meninos quanto meninas tivessem acesso a ela (PAZICH, 2015, p. 150). Isso, inegavelmente, foi reflexo do sistema de reserva desenvolvido com a finalidade de compensar as desigualdades historicamente conformadas pelo sistema de castas e profundamente consolidado na sociedade indiana, ressalvou Pazich (2015, p. 142-143), que, ainda nesse contexto, apresentou referência positiva acerca dos dados apurados pelo Office of the Registrar General $\mathcal{E}$ Census Commissioner, no ano de 2011, segundo o qual houve signiticativas 
melhoras quanto ao nível de instrução de homens e mulhes, comparativamente, entre a população indiana e a do Estado de Kerala (PAZICH, 2015, p. 147):

Quadro 1 - Demonstrativo dos Índices de Instrução

\begin{tabular}{|l|c|c|}
\hline \multicolumn{2}{|c|}{ Índices de Instrução de Homens e Mulheres na Índia e Kerala (2011) } \\
\hline & Índia & Kerala \\
\hline População Total & $72,99 \%$ & $94,00 \%$ \\
\hline População Masculina & $80,89 \%$ & $96,11 \%$ \\
\hline População Feminina & $64,64 \%$ & $92,07 \%$ \\
\hline
\end{tabular}

Fonte: Office of the Registrar General \& Census Commissioner. Census of India 2011: Final population totals: Dashboard (2011).

\section{A PERSISTÊNCIA DA EXCLUSÃO NA ÍNDIA}

Peculiaridades muito específicas fizeram da Índia um ambiente intrigante do ponto de vista da investigação social. Há grupos opressores e oprimidos que pertencem à mesma casta, o que distingue essa sociedade das demais, descritas de forma simplificada como heterogêneas, nas quais prevalece a polarização social, fortemente determinada com base na raça, na cor, no gênero, na religião ou na origem (tome-se como exemplo a sociedade norte-americana quanto ao aspecto racial). Nessa ordem, para se servir de referencial numérico, apenas $9 \%$ da população jovem indiana tem acesso ao Ensino Superior, enquanto, nos países de economia avançada, esse percentual se situa entre 50\% e 70\% (GUPTA, 2006, p. 3). Por conseguinte, um percentual tão reduzido (9\%) pode ser mais sugestivo como decorrência do processo de opressão/exclusão, do que propriamente fator de ordem econômica ou política (DESHPANDE, 2006, p. 2). Aliado a isso, entende-se que, se, no passado, a Universidade assumiu o papel de atender às elites com a proposta de formação das lideranças, hoje dela se exige proposta de massificação do Ensino Superior, de modo a promover, por um lado, a equidade e a justiça e, por outro lado, manter níveis aceitáveis de eficiência, qualidade e responsabilidade pública (GUPTA, 2006, p. 4). Desse modo, talvez seja papel da Universidade, na Índia, hoje, o de conciliar os dois sistemas vigentes: o de castas com o de cotas.

No caso da Índia, as discriminações de dupla forma são baseadas ostensivamente em castas e gêneros, constituindo-se em um sistema profundamente arraigado nas relações sociais, culturais e políticas, de sorte que o emprego de ações afirmativas deve ser compreendido na dimensão dessas variáveis relacionais (GUPTA, 2006, p. 5). Ocorre que o sistema de castas indiano, que pode ser traduzido como sistema de rígida hierarquização social, ainda se mantém, assim como o estado de pobreza dos "intocáveis" tornou-se mais acentuado (PRAKASH, 2009, p. 2). A rigor, a realidade segue demonstrando que os dalits continuam sendo alvo de discriminação, opressão, violência e exclusão (DESHPANDE, 2006, p. 2), tudo isso, porém, coexistindo com o sistema de cotas.

Percebe-se, ademais, que há fatores existenciais os quais envolvem os dalits, compreendidos em níveis de prejuízos sociais e, devido a isso, por se tratar de grupos marcados por 
identidade étnica intensamente estigmatizada, seus integrantes optaram em larga escala pela mudança de suas religiões, convertendo-se uns ao Cristianismo e outros ao Islamismo, o que tem sido descrito como estratégia para fugirem da discriminação e da exclusão. Exemplo disso é que, hoje, na Índia, ao se referir a alguém como "neo-budista", está-se referindo a um "ex-intocável", portanto a alguém que se converteu ao Budismo (DESHPANDE, 2006, p. 3), sendo essa a realidade a qual se traduz na coexistência admitida pela conveniência social e política da presença das religiões mais abrangentes em termos globais, como consequência do processo de exclusão vivenciado na Índia.

Embora essa perspectiva sugira que houve ampla liberdade para a conversão religiosa em face dos descontentamentos e das preferências individuais, essa não foi a realidade, pois, segundo Cassan, havia propostas legislativas apresentadas com o propósito de excluir benefícios dos Scheduled Groups convertidos ao Cristianismo ou ao Islamismo. Entretanto, como os debates em torno desse assunto foram se perpetuando sem definição precisa e imediata, a Assembleia Legislativa Federal, também conhecida como Lok Sabha, foi dissolvida no ano de 1970, antes mesmo que tais projetos fossem aprovados (CASSAN, 2014, p. 5).

Ainda tratando de dificuldades existenciais, há legislação na Índia que busca enfrentar o que se pode chamar de "vergonha do indianismo", dispondo sobre a extinção dos grupos dos párias, a partir do apoio obtido de grupos reformadores e de legisladores. Entretanto, os chamados hindus ortodoxos, que são os religiosos mais rigorosos, tanto na tradição quanto em seus privilégios, opuseram grande resistência a essa legislação, de modo que nada de substancial mudou em relação aos "intocáveis" (CAMPOS NETO, 2009, p. 84).

\section{AVALIAÇÃO DO IMPACTO DA POLÍTICA PÚBLICA DE COTAS}

Partindo de perspectiva estritamente pragmática quanto à avaliação de resultados, não se pode afirmar que o sistema de cotas instituído na Índia, fundamentalmente orientado para favorecer o acesso de pessoas pertencentes aos grupos mais atrasados ao ensino e aos cargos públicos, tenha alcançado êxito minimamente satisfatório, uma vez que, embora a realidade social atualmente vivida naquele país seja melhor do que a do passado, o fato é que isso não se deve precipuamente à adoção do sistema de cotas. Nesse aspecto, para se ter exemplo claro, Loni Pazich apurou que, mesmo considerando que tenha sido proveitosa a facilitação de acesso das mulheres e das castas catalogadas à educação superior, houve considerável concentração dos membros favorecidos com essas cotas nos cursos das áreas de Artes e de Ciências, estimando-se que aproximadamente $80 \%$ dos estudantes favorecidos estavam matriculados, no ano de 2008, nos cursos indicados (PAZICH, 2015, p. 155). Entretanto, no mesmo período, apenas $10 \%$ desses mesmos estudantes conseguiram ter acesso aos cursos de Engenharia e Medicina, os quais são reconhecidos como os mais prestigiados e valorizados como meio para o ingresso no mercado de trabalho (PAZICH, 2015, p. 155). Nessa ordem, segundo Loni Pazich, os estudantes favorecidos com as cotas estão sobre-representados nos cursos de Artes e de Ciências, mas estão sub-representados nos cursos politécnicos, os quais, 
na prática, são os que conduzem aos empregos de melhor padrão remuneratório (PAZICH, 2015, p. 156).

Nesse aspecto, conforme com o que foi anteriormente mencionado, políticas públicas de ações afirmativas têm sido empregadas na atualidade em muitos países, incluindo o Brasil, com o objetivo de promover avanços sociais em favor de grupos considerados historicamente desfavorecidos. Em torno desse tema, debates sobre o impacto do sistema de preferências têm sido intensificados segundo a perspectiva do desempenho educacional e dos possíveis resultados quanto à obtenção de trabalho pelos integrantes dos grupos favorecidos (ROBLES; KRISHNA, 2012, p. 2). Para compreender um pouco mais sobre essa (nova) realidade, Verónica Robles e Kala Krishna, pesquisadoras da Pennsylvania State University, desenvolveram estudos sobre o impacto das políticas de ações afirmativas no Ensino Superior voltadas para estudantes pertencentes a grupos minoritários na Índia.

As pesquisadoras justificaram o enfoque dado à Índia especialmente devido à circunstância de que, nesse país, os critérios de admissão são claros e dirigidos para o que realmente importa, ou seja, para o desempenho dos estudantes nos exames de admissão e na avaliação do abandono escolar, a posteriori. Além disso, elas destacaram que o sistema de cotas indiano é o mais rigoroso e vinculativo para o acesso ao Ensino Superior em favor dos grupos catalogados (ROBLES; KRISHNA, 2012, p. 3).

Nessa avaliação, as pesquisadoras identificaram aspecto negativo no tocante à medida da qualidade dos estudantes favorecidos com cotas, que se formaram nas instituições de Ensino Superior, uma vez que as faculdades são forçadas a admitirem estudantes pelo regime de cotas, o que, em alguns Estados, chega a alcançar até 50\% das vagas existentes (ROBLES; KRISHNA, 2012, p. 6). Verónica e Kala identificaram que os estudantes dos grupos minoritários favorecidos com as cotas apresentaram credenciais acadêmicas significativamente mais fracas do que aqueles outros estudantes não minoritários (CASSAN, 2014, p. 15). Desse modo, os estudantes dos grupos minoritários que frequentaram instituições de Ensino Superior, em decorrência de programas de ações afirmativas, que são mais rigorosas em seus processos seletivos, apresentaram notas mais baixas do que as que teriam obtido em processos menos seletivos. Nessa ordem, seus resultados para ingresso no mercado de trabalho podem ser prejudicados devido às preferências de admissões (ROBLES; KRISHNA, 2012, p. 6-7).

Uma referência ilustrativa dessa realidade foi obtida com estudo detalhado de dados, no ano de 2008, sobre diversos cursos de graduação mantidos pelo Indian Institute of Technology (IIT) em Dehli. De acordo com Verónica e Kala, os dados avaliativos das médias de aproveitamento de estudantes pertencentes às minorias favorecidas (SCs e STs) com as cotas e as médias gerais, que compreendem todos os estudantes (favorecidos e não favorecidos), revelaram a defasagem dos primeiros (ROBLES; KRISHNA, 2012, p. 4): 
Quadro 2 - Demonstrativo de Médias por Cursos

\begin{tabular}{|l|c|c|}
\hline \multicolumn{3}{|c|}{ Médias Aferidas no Primeiro Ano dos Cursos - ITT } \\
\hline \multicolumn{1}{|c|}{ Bacharelado em: } & Média Geral: & Média dos Estudantes Favorecidos (SCs e STs): \\
\hline Ciências da Compuação & 8,56 & 6,65 \\
\hline Eng. Elétrica de Potência & 8,03 & 6,37 \\
\hline Eng. Mecância de Produção & 7,72 & 5,59 \\
\hline Engenharia Elétrica & 7,74 & 5,99 \\
\hline Engenharia Mecânica & 7,57 & 5,50 \\
\hline Engenharia Física & 6,90 & 6,44 \\
\hline Engenharia Química & 7,19 & 5,31 \\
\hline Tecnologia Têxtil & 7,01 & 5,19 \\
\hline
\end{tabular}

Fonte: (ROBLES; KRISHNA, 2012, p. 40).

Ao lado disso, embora os estudantes minoritários façam o Joint Entrance Examination (Exame de Admissão) como os demais estudantes, e a lei indiana lhes dê direito às preferências, tem-se que a sociedade hindu segue tradicionalmente o regime de castas, o qual é determinante quanto às especificações das ocupações. Por conseguinte, os indivíduos oriundos das castas inferiores findam por serem direcionados para o exercício de atividades menos atraentes no mercado de trabalho tanto em termos de prestígio quanto em termos de salários (ROBLES; KRISHNA, 2012, p. 8). Então, no contexto desse processo de avaliação do sistema de cotas, caberia indagar por que o Governo indiano associou o sistema de cotas às castas e não a outro fator social ou econômico?

Para entender essa opção e o dinamismo a ela associado, é preciso considerar dois fatores: primeiro, com o emprego de ações afirmativas, os governos acreditavam que poderiam direcionar os grupos minoritários os quais buscavam objetivos relacionados com a diversidade, harmonia e o progresso social (GUPTA, 2006, p. 3) e, segundo, o emprego da raça ou da casta poderia ser substituído pela renda das pessoas, como fator para direcionar as políticas sociais (ROBLES; KRISHNA, 2012, p. 11). Entretanto, como os grupos minoritários na Índia foram colocados para exercerem atividades laborais menos prestigiadas e com baixos salários, o Governo optou por adotar políticas públicas baseadas em castas como fator substitutivo da renda, justificando que a primeira seria mais eficiente para identificar os grupos verdadeiramente desfavorecidos, pois se admitia que o status da casta seria mais difícil de falsear do que o da renda. Em verdade, na Índia, é especialmente difícil identificar a renda das pessoas, uma vez que $92 \%$ da força de trabalho ativa naquele país é composta de trabalhadores informais (ROBLES; KRISHNA, 2012, p. 11-12).

Diante desse quadro circunstancial, Verónica e Kala identificaram evidências de que os grupos minoritários de estudantes não estão se recuperando em termos de desempenho acadêmico e concluíram que os estudantes oriundos das SCs e das STs, quando inseridos nos ambientes escolares mais seletivos, tendem a se atrasar em seus rankings (notas), o que parece confirmar a "hipótese de incompatibilidade", segundo a qual se preveem taxas de sucesso inferiores para os estudantes dos grupos minoritários que ingressaram em instituições 
de ensino mais seletivas (ROBLES; KRISHNA, 2012, p. 21). O estudo sugere, portanto, que os estudantes dos grupos minoritários, quando inseridos em espaços educacionais mais seletivos, não conseguem acompanhar os demais, confirmando-se a "hipótese de incompatibilidade". Além disso, essa realidade produz consequências para a obtenção de emprego, devido ao critério da seletividade, uma vez que os grupos minoritários ocupam postos de trabalho inferiores, comparando-os com os demais estudantes em geral (ROBLES; KRISHNA, 2012, p. 34).

Ademais, fica absolutamente claro que mais de meio século de discriminação positiva falhou substancialmente para enfrentar as desvantagens que marcam a condição existencial da maioria das SCs e das STs. Além disso, a persistência do subdesenvolvimento humano dos mais pobres endossa o fato de que a criação de oportunidades não levou à melhoria material das pessoas. Aqueles que estão no fundo da ordem ritual das castas ou às margens da sociedade continuam a carregar múltiplos encargos de negação e de privação. Esse fracasso pode bem ser atribuído às hierarquias sociais entrincheiradas que subscrevem o domínio das castas e das classes superiores na sociedade indiana (HEYER; JAYAL, 2009, p. 18), o que confirma a conclusão de Sowell, no sentido de que "a maioria dos realmente pobres é pouco afetada pelas preferências e cotas instituídas em seu nome.” (SOWEL, 2016, p. 70).

Nessa ordem, deve-se ponderar se há satisfação em simplesmente fazer alguma coisa sem considerar as consequências reais, quando verdadeiramente não se pode fugir à conclusão de que a "ação afirmativa na Índia produziu benefícios mínimos para os mais necessitados, além de ressentimentos e hostilidades máximos contra eles por parte de outros." (SOWEL, 2016, p. 72).

\section{CONCLUSÃO}

Inegavelmente, a avaliação sobre a impactação das políticas públicas instituídas no âmbito internacional, tendo como foco os diversos sistemas de cotas, pode ser medida que facilitará, por exemplo, a compreensão, de forma sistematizada, de como as nações têm se ocupado diante das consequências resultantes da implantação desses mecanismos de ações afirmativas. Nessa ordem, o dinamismo social e político vivenciado na Índia conduziu à constatação de resultados particularmente importantes, o que confirma, por exemplo, a perspectiva de que as diferenças das organizações sociais, políticas, econômicas, jurídicas e religiosas podem exercer influências qualitativas quanto ao emprego de cotas, instituídas e dirigidas com a pretensão de alcançar padrão de nivelamento das sociedades.

Partindo desse entendimento, tendo em vista as informações apuradas neste estudo, pode-se concluir que, na Índia, o modelo que conjuga a ordem política com a ordem religiosa talvez seja a marca definidora de seu status sóciopolítico, em que o racionalismo jurídico teve de se ajustar aos padrões e aos valores informados pela ordem religiosa de uma sociedade multifragmentada em torno de múltiplas crenças e centenas de padrões linguísticos, em que, para muitos, a repulsa a grupos sociais considerados inferiores e a própria aceitação por esses 
grupos da repulsa que é imposta a eles. A partir dessa premissa, decorre em boa medida a exclusão de milhões de pessoas, algo que é aceito não em razão de um regime de autoridade ou de força estatal, mas sim, antes e principalmente, em razão de sua aceitação moral, que se sustenta na crença de que nisso reside a própria elevação espiritual.

Nesse contexto, o sistema de cotas instituído em favor dos grupos catalogados como pessoas desafortunadas e desassistidas tem se revelado de eficácia ínfima, ainda mais considerando que há enorme efetivo humano que é mantido excluído socialmente e não acobertado pelo sistema de cotas, a despeito de haver previsão constitucional e legal sobre isso. Ademais, em meio a todo esse quebra-cabeças que se estabeleceu em razão da conjugação dos sistemas de castas e de cotas, foi possível alcançar a elevação do nível social de poucos grupos das baixas castas apenas pontualmente, como consequência direta da elevação do nível de educação escolar das mulheres integrantes desses grupos, de modo que rigorosamente a impactação decorrente do emprego de cotas na Índia não é algo verdadeiramente expressivo e eficaz diante da força religiosa, vigorosamente imposta pelo regime de castas, o que concorre para a manutenção do precário padrão de desenvolvimento humano.

Por derradeiro, verifica-se que os programas de ações afirmativas contribuíram de forma minimamente significativa para a redução do preconceito e da estigmatização dos grupos desfavorecidos, de modo que não é exagero concluir que o preconceito e o separatismo entre grupos são realidades que ainda se mantêm em ritmo contínuo na sociedade indiana.

Em resumo, parece claro que os atuais regimes da ordem social e política na Índia seguem factual e ideologicamente estruturados em dois sistemas paradoxalmente contraditórios, mas convenientemente associados: enquanto, por um lado, o sistema de castas continua sendo o principal fator identitário e da fragmentação da sociedade indiana, além de propulsor das desigualdades verificadas em toda a extensão dessa mesma sociedade, o sistema de cotas, por outro lado, tem a função estratégica de atuar como redutor das desigualdades, ainda que não seja mecanismo eficiente e de larga abrangência, de modo que, enquanto um sistema exclui e fragmenta (castas), sistemática e continuamente, o outro inclui de forma limitada e politicamente articulada (cotas), em pequenas proporções.

\section{REFERÊNCIAS}

BERTRAND, Marianne; HANNA, Rema; MULLAINATHAN, Sendhil. Affirmative action in education: evidence from engineering college admissions in India. Journal of Public Economics, v. 94, n. 1/2, p. 16-29, Feb. 2010. Disponível em: < http://www.nber. org/papers/w13926>. Acesso em: 28 ago. 2017.

BOROOAH, Vani K. Caste, inequality, and poverty in India. Review of Development Economics, Iowa State University, v. 9, Issue 3, p. 399-414, Aug. 2005. Disponível em: <http://onlinelibrary.wiley.com/doi/10.1111/j.1467-9361.2005.00284.x/full>. Acesso em: 24 ago. 2017. 
CAMPOS NETO, Antonio Augusto Machado de. O hinduísmo, o direito hindu, o direito indiano. Revista de Direito, Universidade de São Paulo, v. 104, p. 71-111, jan./dez. 2009. Disponível em: <https://www.revistas.usp.br/rfdusp/article/download/67850/70458>. Acesso em: 5 set. 2017.

CASSAN, Guilhem. The impact of positive discrimination in education in India: evidence from a natural experiment. 2014. p. 1-52. Disponível em: < http://citeseerx.ist. psu.edu/viewdoc/download?doi $=10.1 .1 .407 .1448 \&$ rep $=$ rep $1 \&$ type $=p d f>$. Acesso em: 22 ago. 2017.

CENTRE FOR BUDGET AND GOVERNANCE ACCOUNTABILITY. Manual on inequality in India: major dimensions and policy concerns. New Delhi, 2015. p. 1-24. Disponível em: <http://www.cbgaindia.org/wp-content/uploads/2016/03/Manual-onInequality-in-India.pdf $>$. Acesso em: 22 ago. 2017.

CHANDOLA, M. Varn. Affirmative action in India and the United States: the untouchable and Black experience. Indiana International \& Comparative Law Review, Indianapolis, v. 3, n. 1, p. 101-133, jan. 1992. Disponível em: < https://journals. iupui.edu/index.php/iiclr/article/view/17475>. Acesso em: 22 ago. 2017.

COUTINHO, Diogo R. O direito nas políticas públicas. In: MARQUES, Eduardo; FARIA, Carlos Aurélio Pimenta de (Orgs.). A política pública como campo multidisciplinar. São Paulo: Editora Unesp; Rio de Janeiro: Editora Fiocruz, 2013.

DESHPANDE, Ashwini. Affirmative action in India and the United States. World Development Report Background Papers, World Bank Group. Washington DC, p. 1-23, 2006. Disponível em: <https://openknowledge.worldbank.org/handle/10986/9038>. Acesso em: 4 set. 2017.

DESHPANDE, Manali S. History of the Indian caste system and its impact on India today. California Polytechnic State University, San Luis Obispo, p. 1-35, fall 2010. Disponível em: < http://digitalcommons.calpoly.edu/cgi/viewcontent.cgi?article $=1043$ \&c ontext $=$ socssp $>$. Acesso em: 22 ago. 2017.

DUARTE, Evandro C. Piza; GUELFI, Wanirley Pedroso. Cotas raciais, política identitária e reivindicação de direitos. In: DUARTE, Evandro C. P.; BERTÚLIO, Dora L. L.; SILVA, Paulo V. B. (Coord.). Cotas Raciais no Ensino Superior: entre o jurídico e o político. Curitiba: Juruá, 2012. p. 121-158.

GUPTA, Asha. Affirmative action in higher education in India and The US: a study in contrasts. Center for Studies in Higher Education, Berkeley, p. 1-19, jun. 2006. Disponível em: <http://escholarship.org/uc/item/5nz5695t>. Acesso em: 1 set. 2017. 
HARRISS-WHITE, Barbara; PRAKASH, Aseem. Social discrimination in India: a case for economic citizenship. Working Papers Series, India, p. 1-37, Sept. 2010. Disponível em: <https://www.oxfamindia.org/sites/default/files/VIII.\%20Social\% 20Discrimination\%20in\%20India-20A\%20Case\%20for\%20Economic\%20Citizenship. pdf>. Acesso em: 22 ago. 2017.

HEYER, Judith; JAYAL, Niraja Gopal. The challenge of positive discrimination in India. Center of Research on Inequality, Human Security and Ethnicity, University of Oxford. Mansfield, p. 1-33, Feb. 2009. Disponível em: <http://www3.qeh.ox.ac.uk/pdf/crisewps/ workingpaper55.pdf>. Acesso em: 24 ago. 2017.

HIRANO, Sedi. Castas, estamentos e classes sociais: introdução ao pensamento sociológico de Marx e Weber. 3. ed. Campinas: Editora da Unicamp, 2002.

HOFBAUER, Andreas. Racismo na Índia? Cor, raça e casta em contexto. Revista Brasileira de Ciência Política, Brasília, n. 6, p. 153-191, jan./abr. 2015. Disponível em: <http://www.scielo.br/scielo.php?pid=S0103-33522015000200153\&script $=$ sci_ abstract\&tlng=es $>$. Acesso em: 31 ago. 2017.

HOWARD, Larry L.; PRAKASH, Nishith. Do employment quotas explain the occupational choices of disadvantaged minorities in India? Institute for the Study of Labor, Germany, p. 1-35, jul. 2011. Disponível em: < http://ftp.iza.org/dp5894.pdf>. Acesso em: 29 ago. 2017.

JANGIR, Sunil Kumar. Reservation policy and Indian Constitution in India. American International Journal of Research in Humanities, Arts and Social Sciences, Georgia, p. 13-225, 2013. Disponível em: <http://iasir.net/AIJRHASSpapers/AIJRHASS13-225. pdf >. Acesso em: 26 set. 2017.

KEDIA, Bineet. Affirmative actions in India and US: challenge to reservation policy in India. International Journal of Law and Legal Jurisprudence Studies, India, v. 2, Issue 1, p. 1-20, jan. 2015. Disponível em: < http://ijlljs.in/wp-content/uploads/2015/01/ AFFIRMATIVE-ACTIONS-IN-INDIA-AND-US.pdf>. Acesso em: 28 ago. 2017.

KUMAR, Vivek. Inequality in India: caste and Hindu social order. Transcience Journal of Global Studies, Jawaharlal Nehru University, New Delhi, India, v. 5, Issue 1, p. 36-52, 2014. Disponível em: < https://www2.hu-berlin.de/transcience/Vol5_No1_2014_36_52. pdf>. Acesso em: 22 ago. 2017.

MALTEZ, José Adelino. Tópicos Jurídicos e Políticos. 2009. Disponível em: $<$ http://maltez.info/aaanetnovabiografia/Conceitos/Casta.htm>. Acesso em: 22 ago. 2017.

MASCARENHAS, António Constâncio d'Expetação Brás. As castas da Índia: esboço de estudo antropo-social. Portugal: Imprensa Nacional, 1924. Disponível em: < https:// 
repositorio-aberto.up.pt/bitstream/10216/17593/3/208_4_FMP_TD_I_01_P.pdf >. Acesso em: 6 out. 2017.

MEHRA, Ajay K. O sistema político partidário da Índia. Partidos Políticos: Quatro Continentes. Cadernos Adenauer VIII, Rio de Janeiro, n. 3, p. 75-100, 2007. Disponível em: <http://www.kas.de/wf/doc/9470-1442-5-30.pdf>. Acesso em: 8 set. 2017.

NARULA, Smita. Equal by law, unequal by caste: the "untouchable" condition in critical race perspective. Wisconsin International Law Journal, Madison, v. 26, n. 2, p. 255-343, Sept. 2008. Disponível em: < https://papers.ssrn.com/sol3/papers.cfm?abstract_ $\mathrm{id}=1273803>$. Acesso em: 22 ago. 2017.

OFFICE OF THE REGISTRAR GENERAL \& CENSUS COMMISSIONER. Census of India 2011: Final population totals: Dashboard. CensusInfo India 2011. Disponível em: $<$ http://www.censusindia.gov.in/2011census/censusinfodashboard/index.html $>$. Acesso em: 25 set. 2017.

PAZICH, Loni Bordoloi Bordoloi. Ação afirmativa na educação superior: o caso de Kerala na Índia. Tradução Karin Quast. Educação \& Sociedade, Campinas, v. 36, n. 130, p. 139-159, jan./mar. 2015. Disponível em: <http://www.redalyc.org/articulo. oa? $\mathrm{id}=87339466009>$. Acesso em: 31 ago. 2017.

PRAKASH, Nishith. The impact of employment quotas on the economic lives of disadvantaged minorities in India. 2009. p. 1-56. Disponível em: <http://www. dartmouth.edu/ prakash/Prakash_Job_Market_2010.pdf>. Acesso em: 24 ago. 2017.

RAI, Shirin M. Democratic institutions, political representation and women's empowerment: the quota debate in India. Journal Democratization, Abingdon, UK, v. 6, n. 3, p. 84-89, Sept. 1999. Disponível em: <http://www.tandfonline.com/doi/ abs/10.1080/13510349908403622 >. Acesso em: 24 ago. 2017.

ROBLES, Verónica Frisancho; KRISHNA, Kala. Affirmative action in higher education in India: targeting, catch up, and mismatch at IIT-Delhi. National Bureau of Economic Research, Cambridge, n. 17727, p. 1-44, jan. 2012. Disponível em: <http://www.isid.ac.in/ pu/ conference/dec_11_conf/Papers/VeronicaFrisanchoRobles.pdf>. Acesso em: 25 set. 2017. SAREEN, Dhruva; SHAH, Purav. Comparative analyses of affirmative action in India and USA: affirming the affirmative, National Law University Jodhpur. India, p. 1-33, Oct. 2013. Disponível em: <https://papers.ssrn.com/sol3/papers.cfm?abstract_id $=2336621>$. Acesso em: 24 ago. 2017.

SOWELL, Thomas. Ação afirmativa ao redor do mundo: um estudo empírico sobre as cotas e grupos preferenciais. Tradução Joubert de Oliveira Brízida. São Paulo: É Realizações, 2016. 
VITHAYATHIL, Trina; SINGH, Gayatri. Spaces of discrimination: residential segregation in Indian cities. Economic \& Political Weekly, Mumbai, India, v. 47, n. 37, p. 60-66, Sept. 2012. Disponível em: <http://www.epw.in/system/files/pdf/2012_47/37/ Spaces\%20of\%20. Discrimination.pdf>. Acesso em: 22 ago. 2017.

WADE, Nicholas. A troublesome inheritance: genes, race and human history. New York: Penguin Books, 2015. 